\title{
Cutaneous melanoma primary site is linked to nevus density
} This article has been corrected. Correction in Oncotarget. 2018; 9:36816-36816.

\section{Alejandro Martin-Gorgojo ${ }^{1, *}$, Marta Llinares ${ }^{2, *}$, Amaya Virós $^{3,4, *}$, Celia Requena ${ }^{2}$,} Zaida Garcia-Casado ${ }^{5}$, Víctor Traves ${ }^{6}$, Rajiv Kumar7 and Eduardo Nagore $^{2,8}$

\footnotetext{
${ }^{1}$ Escuela de Doctorado, Universidad Católica de Valencia "San Vicente Mártir", Valencia, Spain

${ }^{2}$ Department of Dermatology, Instituto Valenciano de Oncologia (IVO), Valencia, Spain

${ }^{3}$ Skin Cancer and Ageing Laboratory, CRUK Manchester Institute, Manchester, UK

${ }^{4}$ Salford Royal NHS Foundation Trust, Manchester, UK

${ }^{5}$ Department of Molecular Biology, Instituto Valenciano de Oncologia (IVO), Valencia, Spain

${ }^{6}$ Department of Pathology, Instituto Valenciano de Oncologia (IVO), Valencia, Spain

${ }^{7}$ Division of Molecular Genetic Epidemiology, German Cancer Research Center, Heidelberg, Germany

${ }^{8}$ Dermatology Department, School of Medicine, Universidad Católica de València "San Vicente Mártir", Valencia, Spain

*These authors have contributed equally to this work
}

Correspondence to: Eduardo Nagore, email: eduardo.nagore@ucv.es

Keywords: melanoma; nevus; risk; sunburn; solar elastosis

Received: July 20, $2017 \quad$ Accepted: September 23, $2017 \quad$ Published: October 24, 2017

Copyright: Martin-Gorgojo et al. This is an open-access article distributed under the terms of the Creative Commons Attribution License 3.0 (CC BY 3.0), which permits unrestricted use, distribution, and reproduction in any medium, provided the original author and source are credited.

\section{ABSTRACT}

There are at least two pathways driving cutaneous melanoma; one is linked to an inherent melanoma susceptibility to nevi development and the second to environmental cumulative ultraviolet light exposure. In this study, we examined the relation between nevus density, accrued sun damage and the site of primary melanoma excision.

In a series of 888 consecutive cutaneous melanoma patients, melanomas appearing in skin areas with a high relative nevus density were most prominent in men, with an elevated nevus count, at sites without solar elastosis, but with an epidemiological history of previous sunburn.

The present study associates melanoma development to sites with high nevus density. Our study supports more careful surveillance of body areas with increased nevus density in patients with high total body number of nevi, especially when they report a history of sunburns at these sites.

\section{INTRODUCTION}

By studying risk behavior and epidemiological characteristics of melanoma patients, Whiteman et al. proposed a dual pathway to melanoma acquisition $[1$, 2]. One possible route to melanoma is the nevus-prone pathway, where intrinsic predisposition to melanocytic proliferation drives the presence of a high number of melanocytic benign and atypical nevi [3, 4]. On the other hand, a second path links the accumulation of cutaneous actinic damage throughout life, or excessive chronic or intermittent ultraviolet radiation (UVR) exposure, to melanoma [2]. Patients developing melanoma through this second pathway have typically fair skin and signs of chronic sun damage, other UVR-related non-melanoma skin cancers and the expression of p53 protein in the primary tumor [4].

Although the nevus-prone pathway underpins melanoma patients with multiple nevi, it is unclear whether the primary melanoma in this context is more likely to arise at sites where the number of nevi is highest [5-9]. Nevi are not distributed homogeneously on the body and their location can be influenced by genetic and environmental (UVR) factors, so we investigated whether the site of primary melanoma is related to the relative density of nevi on the cutaneous area where it arises. Here 
we present the clinical and epidemiological features of primary melanoma in relation to the nevus density at the site they develop, and investigate the care implications.

\section{RESULTS}

Out of 2052 patients included in the database, 1550 had newly diagnosed melanomas, and 1110 individuals had sporadic invasive cutaneous melanomas, of whom a total of 888 patients had sufficient data recorded to calculate both the total nevus density and the nevus density at the melanoma region. The characteristics of the studied population are detailed in Table 1.

When patients were grouped according to the nevus density at the melanoma region, a high nevus density was significantly associated with young age at presentation, a high total body nevus count and density, and presence of one or more non-synonymous MC1R variants. These patients more frequently presented the melanoma on the trunk and had a history of intermittent sun exposure where the patient recalled having had sunburns in the past. The tumor was mainly of the SSM subtype and presented without histological signs of chronic sun damage (absent solar elastosis, non-CSD) (Table 1).

When comparing patients classified by the sitespecific relative nevus density, melanomas located on an area with a higher nevus density than the total body density occurred more frequently in patients who were men $(53.3 \%)$, were 45 years of age or younger $(39.1 \%)$ and had a high total body nevus density $(49.1 \%$ had $>10.6 \mathrm{nevi} / \mathrm{m}^{2}$ ). The frequency of patients with increased relative nevus density at melanoma site increased progressively with increase in total body nevus density; with $18.3 \%[50 / 273]$ in the group with $<2.45 \mathrm{nevi} / \mathrm{m}^{2}$, $52.8 \%[160 / 303]$ in the group with $2.45-10.60 \mathrm{nevi} / \mathrm{m}^{2}$ and $69.2 \%[211 / 303]$ in the group with $>10.60 \mathrm{nevi} / \mathrm{m}^{2}$. In addition, the SSM subtype tumors were more frequent (73.7\% of patients), developed in intermittently sunexposed areas ( $85 \%$ of patients), and the patients recalled having suffered sunburns. In our study $90 \%$ of patients recalled having suffered at least one sunburn at the site, with $35.7 \%$ remembering at least one severe, blistering sunburn. This epidemiological history was consistent with the presence of solar lentigines $(58.2 \%)$ but absent solar elastosis with $93.5 \%$ of patients compared to $79.9 \%$ in the group with relative nevus density lower than or equal to the total body nevus density. The $32.8 \%$ of primary melanomas had an increased frequency of contiguous neval remnants compared to $18.8 \%$ in the group with low site-specific nevus density (Table 2). The age-adjusted multivariate analysis confirmed a high total body nevus density with $6.5 \mathrm{X}$ for third and $4.2 \mathrm{X}$ for second tertiles. The absence of solar elastosis at the primary melanoma site, and a past history of sunburns at the melanoma site were the relevant variables that significantly associated with the development of tumors in areas with a high relative nevus density (Table 3). Furthermore, we describe a progressive decrease in solar elastosis with increasing melanocyte count in melanoma patients (Figure 1).

\section{DISCUSSION}

In this study using data from 888 melanoma patients we describe the characteristics of melanomas according to total body nevus density and according to nevus density at the site of primary melanoma. Melanomas arising in areas with a high nevus density and the tumors developing in cutaneous areas with a site-specific relative nevus density greater than the total body nevus density are more frequently observed in men with a high total body nevus density and count. These tumors more likely arise in previously sunburned skin areas as recalled by the patient, and the peritumoral skin presents no histological signs of chronic sun damage.

Nevus density and total number of nevi have been known for decades to be an important risk factor to melanoma [10-12]. Total nevus density has been linked to sun exposure [13], lighter phototypes, a history of sunburns in children $[14,15]$, melanomas with contiguous neval remnants [16], familial cases of dysplastic nevus syndrome and melanoma [17], genetic cell-cycle control factors $[18,19]$ such as the CDKN2A gene $[20,21]$ and others [22], as well as an absent p53 expression within melanoma tumor samples, which supports the divergent pathway model $[1,23]$. Although the association between primary tumor site and nevus distribution has been noted this has not yet been studied in depth [24-28] and, therefore, there are currently no clear recommendations regarding variations in regional anatomic or site-specific nevus density.

The present study is, to our knowledge, the first to assess subsets of patients specifically according to both absolute and site-specific relative nevus density in 888 prospectively recruited melanoma patients with inclusion of clinical, histological and genetic susceptibility factors. The data analysis has shown that patients presenting with a higher site-specific relative nevus density are more frequently male, younger, with a higher total body nevus density, a past history of sunburns on the melanoma area, and with histopathological findings showing no chronic sun damage.

Our findings link a higher nevus density at the melanoma area with younger patients, which could be associated to the progressively lower nevus count observed during ageing. Male sex has also proven to be an independent associated factor [24]. This could be due to the higher frequency of melanoma on the back and shoulders in males, areas with overall higher melanocytic nevi counts [3]. Additionally, men report different patterns of sun exposure and behavior [29]. In a similar manner, the SSM histological subtype may be associated to high nevus density due to its overall higher incidence and its 
Table 1: Total population and subgroup (divided following the nevi density on the melanoma area) description, and univariate (Chi-square) analyses results

\begin{tabular}{|c|c|c|c|c|c|c|c|c|c|}
\hline \multirow[t]{2}{*}{ Variable } & \multicolumn{2}{|c|}{$\begin{array}{c}\text { Total } \\
(\mathrm{N}=\mathbf{8 8 8})\end{array}$} & \multicolumn{2}{|c|}{$\begin{array}{c}0 \text { nevus/m² } \\
(\mathrm{N}=339)\end{array}$} & \multicolumn{2}{|c|}{$\begin{array}{c}1-15 \text { nevi } / \mathbf{m}^{2} \\
(\mathrm{~N}=238)\end{array}$} & \multicolumn{2}{|c|}{$\begin{array}{c}>15 \text { nevi } / \mathrm{m}^{2} \\
(\mathrm{~N}=311)\end{array}$} & \multirow{2}{*}{$\begin{array}{c}\mathbf{P} \\
(\mathbf{P c})\end{array}$} \\
\hline & $\mathbf{N}$ & $\%$ & $\mathbf{N}$ & $\%$ & $\mathbf{N}$ & $\%$ & $\mathbf{N}$ & $\%$ & \\
\hline Age (mv: 0) & & & & & & & & & $\begin{array}{c}<0.001 \\
(<0.001)\end{array}$ \\
\hline$-\leq 45$ & 280 & 31.5 & 58 & 17.1 & 75 & 31.5 & 147 & 47.3 & \\
\hline$-46-60$ & 297 & 33.4 & 94 & 27.7 & 95 & 39.9 & 108 & 34.7 & \\
\hline$->60$ & 311 & 35.0 & 187 & 55.2 & 68 & 28.6 & 56 & 18.0 & \\
\hline Sex (mv: $1[0.1 \%])$ & & & & & & & & & $\begin{array}{c}0.009 \\
(0.135)\end{array}$ \\
\hline -Male & 433 & 48.8 & 148 & 43.8 & 112 & 47.1 & 173 & 55.6 & \\
\hline -Female & 454 & 51.2 & 190 & 56.2 & 126 & 52.9 & 138 & 44.4 & \\
\hline Location (mv: 0) & & & & & & & & & $\begin{array}{l}<0.001 \\
(<0.001)\end{array}$ \\
\hline -Head/neck & 161 & 18.1 & 101 & 29.8 & 39 & 16.4 & 21 & 6.8 & \\
\hline -Upper limb & 130 & 14.6 & 48 & 14.2 & 29 & 12.2 & 53 & 17.0 & \\
\hline -Trunk & 358 & 40.3 & 42 & 12.4 & 121 & 50.8 & 195 & 62.7 & \\
\hline -Lower limb & 186 & 20.9 & 101 & 29.8 & 49 & 20.6 & 36 & 11.6 & \\
\hline -Acral & 53 & 6.0 & 47 & 13.9 & 0 & 0.0 & 6 & 1.9 & \\
\hline Sun exposure at melanoma site (mv: 0 ) & & & & & & & & & $\begin{array}{c}<0.001 \\
(<0.001)\end{array}$ \\
\hline -None/rarely & 73 & 8.2 & 51 & 15 & 9 & 3.8 & 13 & 4.2 & \\
\hline -Occasionally & 640 & 72.1 & 180 & 53.1 & 181 & 76.1 & 279 & 89.7 & \\
\hline -Usually & 175 & 19.7 & 108 & 31.9 & 48 & 20.2 & 19 & 6.1 & \\
\hline Number of common nevi (mv: 0 ) & & & & & & & & & $\begin{array}{c}<0.001 \\
(<0.001)\end{array}$ \\
\hline$-<20$ & 590 & 66.4 & 323 & 95.3 & 196 & 82.4 & 71 & 22.8 & \\
\hline$-20-50$ & 161 & 18.1 & 9 & 2.7 & 34 & 14.3 & 118 & 37.9 & \\
\hline$-51-100$ & 92 & 10.4 & 4 & 1.2 & 8 & 3.4 & 80 & 25.7 & \\
\hline$->100$ & 45 & 5.1 & 3 & 0.9 & 0 & 0.0 & 42 & 13.5 & \\
\hline Total body nevi density (mv: 0) & & & & & & & & & $\begin{array}{l}<0.001 \\
(<0.001)\end{array}$ \\
\hline$-<2.5$ & 282 & 31.8 & 223 & 65.8 & 58 & 24.4 & 1 & 0.3 & \\
\hline$-2.5-10.6$ & 303 & 34.1 & 97 & 28.6 & 135 & 56.7 & 71 & 22.8 & \\
\hline$->10.6$ & 303 & 34.1 & 19 & 5.6 & 45 & 18.9 & 239 & 76.8 & \\
\hline Solar lentigines (mv: 12 [1.4\%]) & & & & & & & & & $\begin{array}{c}0.198 \\
(1.0)\end{array}$ \\
\hline -No & 103 & 11.8 & 43 & 12.9 & 32 & 13.6 & 28 & 9.1 & \\
\hline -Yes & 773 & 88.2 & 291 & 87.1 & 203 & 86.4 & 279 & 90.9 & \\
\hline Solar lentigines on MM area (mv:6 [0.7\%]) & & & & & & & & & $\begin{array}{c}0.025 \\
(0.375)\end{array}$ \\
\hline -No & 439 & 49.8 & 183 & 54.5 & 120 & 50.8 & 136 & 43.9 & \\
\hline -Yes & 443 & 50.2 & 153 & 45.5 & 116 & 49.2 & 174 & 56.1 & \\
\hline
\end{tabular}




\begin{tabular}{|c|c|c|c|c|c|c|c|c|c|}
\hline \multirow[t]{2}{*}{ Variable } & \multicolumn{2}{|c|}{$\begin{array}{c}\text { Total } \\
(\mathrm{N}=\mathbf{8 8 8})\end{array}$} & \multicolumn{2}{|c|}{$\begin{array}{c}0 \text { nevus } / \mathbf{m}^{2} \\
(\mathrm{~N}=\mathbf{3 3 9})\end{array}$} & \multicolumn{2}{|c|}{$\begin{array}{c}1-15 \mathrm{nevi} / \mathrm{m}^{2} \\
(\mathrm{~N}=238)\end{array}$} & \multicolumn{2}{|c|}{$\begin{array}{l}>15 \mathrm{nevi} / \mathrm{m}^{2} \\
\quad(\mathrm{~N}=311)\end{array}$} & \multirow{2}{*}{$\begin{array}{c}P \\
(\mathbf{P c})\end{array}$} \\
\hline & $\mathbf{N}$ & $\%$ & $\mathbf{N}$ & $\%$ & $\mathbf{N}$ & $\%$ & $\mathbf{N}$ & $\%$ & \\
\hline Severe sunburns (mv:1 [0.1\%]) & & & & & & & & & $\begin{array}{c}0.005 \\
(0.075)\end{array}$ \\
\hline -No & 407 & 45.9 & 183 & 54.1 & 105 & 44.1 & 119 & 38.3 & \\
\hline$-1-5$ & 304 & 34.3 & 99 & 29.3 & 85 & 35.7 & 120 & 38.6 & \\
\hline$-6-10$ & 69 & 7.8 & 19 & 5.6 & 22 & 9.2 & 28 & 9.0 & \\
\hline$->10$ & 107 & 12.1 & 37 & 10.9 & 26 & 10.9 & 44 & 14.1 & \\
\hline Sunburns at MM area (mv: $10[1.1 \%])$ & & & & & & & & & $\begin{array}{c}<0.001 \\
(<0.001)\end{array}$ \\
\hline$-\mathrm{No}$ & 276 & 31.4 & 158 & 47.3 & 55 & 23.2 & 63 & 20.5 & \\
\hline -Mild & 359 & 40.9 & 114 & 34.1 & 115 & 48.5 & 130 & 42.3 & \\
\hline -Intense & 243 & 27.7 & 62 & 18.6 & 67 & 28.3 & 114 & 37.1 & \\
\hline Histological subtype (mv: 0) & & & & & & & & & $\begin{array}{c}<0.001 \\
(<0.001)\end{array}$ \\
\hline -LMM & 97 & 10.9 & 67 & 19.8 & 20 & 8.4 & 10 & 3.2 & \\
\hline -SSM & 581 & 65.4 & 175 & 51.6 & 174 & 73.1 & 232 & 74.6 & \\
\hline -NM & 132 & 14.9 & 43 & 12.7 & 32 & 13.4 & 57 & 18.3 & \\
\hline -ALM & 31 & 3.5 & 30 & 8.8 & 0 & 0.0 & 1 & 0.3 & \\
\hline -Other/NOS & 47 & 5.3 & 24 & 7.1 & 12 & 5.0 & 11 & 3.5 & \\
\hline Contiguous neval remnants (mv: $32[3.6 \%]$ ) & & & & & & & & & $\begin{array}{c}<0.001 \\
(>0.001)\end{array}$ \\
\hline -No & 637 & 74.4 & 273 & 83.2 & 165 & 72.7 & 199 & 66.1 & \\
\hline -Yes & 219 & 25.6 & 55 & 16.8 & 62 & 27.3 & 102 & 33.9 & \\
\hline $\operatorname{CSD}(\mathrm{mv}:=301[33.9 \%])$ & & & & & & & & & $\begin{array}{c}<0.001 \\
(<0.001)\end{array}$ \\
\hline$-\mathrm{No}$ & 507 & 86.4 & 178 & 76.1 & 140 & 89.2 & 189 & 96.4 & \\
\hline -Yes & 80 & 13.6 & 56 & 23.9 & 17 & 10.8 & 7 & 3.6 & \\
\hline Stage (mv: 0) & & & & & & & & & $\begin{array}{c}0.958 \\
(1.0)\end{array}$ \\
\hline -In situ & 154 & 17.3 & 62 & 18.3 & 39 & 16.4 & 53 & 17.0 & \\
\hline -Local disease & 617 & 69.5 & 230 & 67.8 & 170 & 71.4 & 217 & 69.8 & \\
\hline -Locoregional & 115 & 13.0 & 46 & 13.6 & 29 & 12.2 & 40 & 12.9 & \\
\hline -Metastatic & 2 & 0.2 & 1 & 0.3 & 0 & 0.0 & 1 & 0.3 & \\
\hline Non-synonymous & & & & & & & & & 0.032 \\
\hline MC1R variants (mv: 0) & & & & & & & & & $(0.480)$ \\
\hline -None & 280 & 33.8 & 118 & 38.2 & 73 & 32.6 & 89 & 30.1 & \\
\hline-1 variant & 332 & 40.0 & 118 & 38.2 & 101 & 45.1 & 113 & 38.2 & \\
\hline$->1$ variant & 217 & 26.2 & 73 & 23.6 & 50 & 22.3 & 94 & 31.8 & \\
\hline
\end{tabular}

mv: missing values.

CSD: severe chronic sun damage on the skin surrounding the melanoma.

P: p-value from Chi squared test.

Pc: p-value corrected by Bonferroni test. 
well-established link to overall higher nevus counts [25]. We also found an increased frequency of contiguous neval remnants at sites of higher nevus density which could be justified by the inherent association of melanoma arising over a nevus, however this question has not been examined in detail.

Our data supports that patients with high overall nevi numbers have a significantly increased risk of presenting a melanoma in areas with a high relative nevus density $[3,25]$. We hypothesize this observation could be due to either a site-specific higher melanocyte proliferation, to the influence of greater sun exposure at this area, or due to a combination of both factors. The strong link between nevus density, primary melanoma site and a prior history of sunburn or intermittent UVR exposure at the same site support the role of sun exposure as a trigger for melanoma development in an already predisposed area [30-32]. The present findings suggest that areas with a high nevus density that have suffered mild or intense sunburns should be clinically examined more carefully, and should probably need to be more meticulously sun protected in order to prevent the increase in the number of nevi, an approach which has been proven especially useful in fairskinned, freckle-prone patients [19].

By contrast, CSD melanomas are confirmed to arise more frequently on chronically sun-exposed areas -such as the head and neck- in patients with non-melanoma skin cancers and a low number of nevi $[2,33,34]$. These data further supports the divergent etiologic pathway model [2].

Importantly, we show that the higher the nevus density at a primary melanoma site, the less likely it is to present CSD. Using CSD as a surrogate marker of cumulative sun damage, our finding strengthens the idea that individuals with increased propensity (susceptibility) to nevus development require less total sun exposure to progress to melanoma. The gradual decline in CSD as the number of nevi increase in our patients supports the idea that the two main pathways for cutaneous melanoma are not mutually exclusive but complimentary, representing two ends of an etiopathological spectrum where a higher inherent nevus propensity requires less UVR cooperation, and in individuals with lower nevus density there is progressive increased UVR involvement for melanomagenesis.

An advantage of our study is that all patient data were collected prospectively, following homogeneous criteria, assessed by the same clinicians within a national tertiary reference center with a wide geographical catchment area. Thus, our cohort is a faithful extrapolation of Spanish melanoma patients. However, certain limitations may affect this study, such as its sample size, the inherent constraints associated to a retrospective approach and the intrinsic recall bias in the history of sunburns at the site of primary melanoma incidence, although the latter affects equally all the patients who did

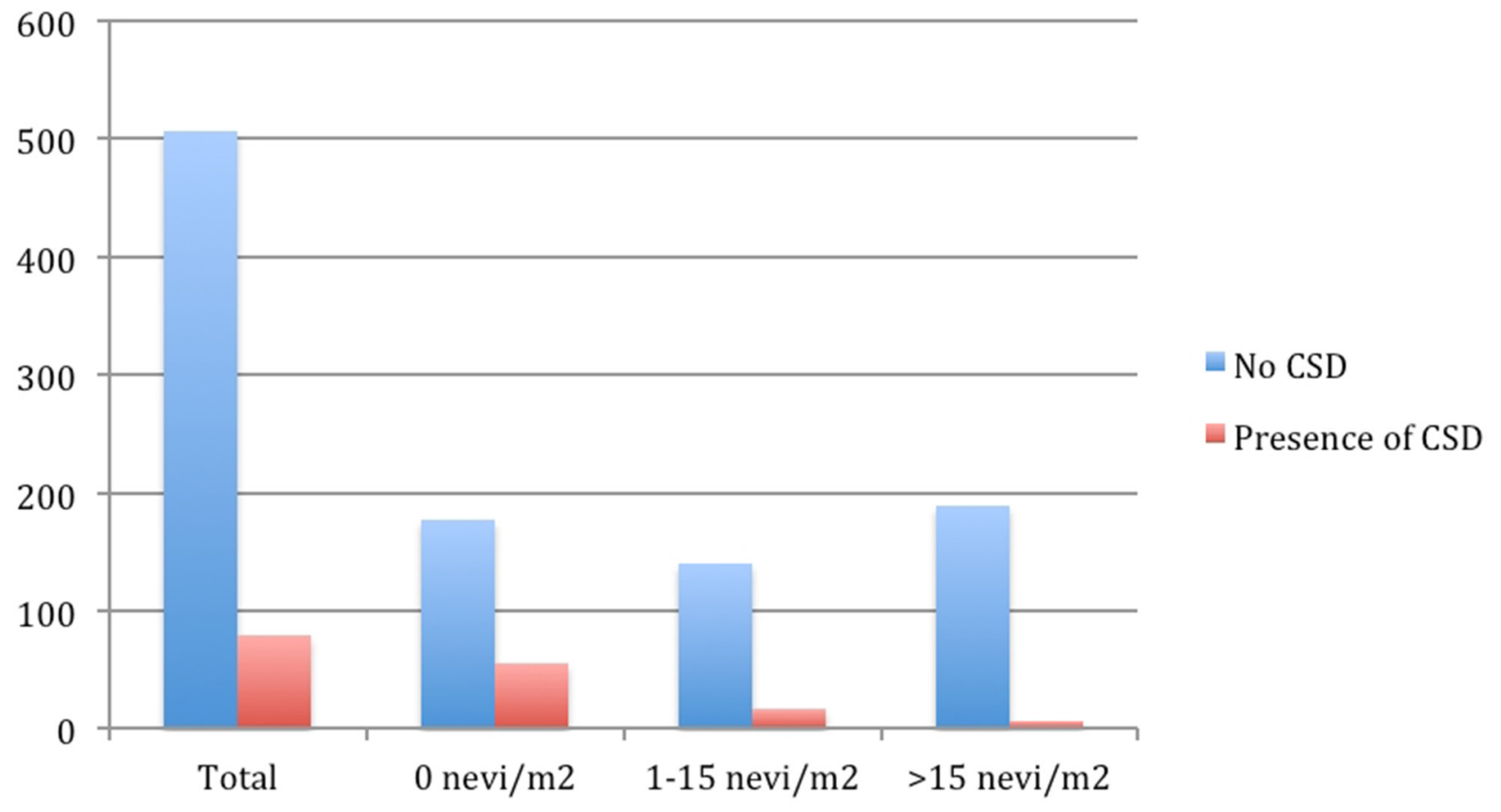

Figure 1: Number of patients showing histological evidence of CSD according to the nevi density on the melanoma area. 
Table 2: Characteristics of the groups defined by the relative nevi density on the melanoma area compared to the total body surface nevi density

\begin{tabular}{|c|c|c|c|c|c|}
\hline \multirow[b]{2}{*}{ Variable } & \multicolumn{2}{|c|}{$\begin{array}{l}\text { Nevi density on the MM area } \\
\text { lower or equal to total body nevi } \\
\text { density }\end{array}$} & \multicolumn{3}{|c|}{$\begin{array}{l}\text { Nevi density on the MM area } \\
\text { higher to total body nevi density }\end{array}$} \\
\hline & $\mathbf{N}$ & $\%$ & $\mathbf{N}$ & $\%$ & $\begin{array}{c}\mathbf{P} \\
(\mathbf{P c})\end{array}$ \\
\hline Age (mv: 0) & & & & & $<0.001$ \\
\hline$-\leq 45$ & 112 & 24.5 & 168 & 39.1 & $(<0.001)$ \\
\hline$-46-60$ & 139 & 30.3 & 158 & 36.7 & \\
\hline$->60$ & 207 & 45.2 & 104 & 24.2 & \\
\hline Sex (mv: $1[0.1 \%])$ & & & & & 0.01 \\
\hline -Male & 204 & 44.6 & 229 & 53.3 & $(0.15)$ \\
\hline -Female & 253 & 55.4 & 201 & 46.7 & \\
\hline Location (mv: 0) & & & & & $<0.001$ \\
\hline -Head/neck & 121 & 26.4 & 40 & 9.3 & $(<0.001)$ \\
\hline -Upper limb & 61 & 13.3 & 69 & 16.0 & \\
\hline -Trunk & 82 & 17.9 & 276 & 64.2 & \\
\hline -Lower limb & 146 & 31.9 & 40 & 9.3 & \\
\hline -Acral & 48 & 10.5 & 5 & 1.2 & \\
\hline $\begin{array}{l}\text { Sun exposure of melanoma site } \\
(\mathrm{mv}: 0)\end{array}$ & & & & & $<0.001$ \\
\hline -None/rarely & 60 & 13.1 & 13 & 3.0 & $(<0.001)$ \\
\hline -Occasionally & 272 & 59.4 & 368 & 85.6 & \\
\hline -Usually & 126 & 27.5 & 49 & 11.4 & \\
\hline Number of common nevi (mv: 0) & & & & & $<0.001$ \\
\hline$-<20$ & 372 & 81.2 & 218 & 50.7 & $(<0.001)$ \\
\hline$-20-50$ & 48 & 10.5 & 113 & 26.3 & \\
\hline$-51-100$ & 22 & 4.8 & 70 & 16.3 & \\
\hline$->100$ & 16 & 3.5 & 29 & 6.7 & \\
\hline Total body nevi density (mv: 0) & & & & & $<0.001$ \\
\hline$-<2.5$ & 223 & 48.7 & 50 & 13.7 & $(<0.001)$ \\
\hline$-2.5-10.6$ & 143 & 31.2 & 160 & 37.2 & \\
\hline$->10.6$ & 92 & 20.1 & 211 & 49.1 & \\
\hline Solar lentigines (mv: 12 [1.4\%]) & & & & & 0.679 \\
\hline$-\mathrm{No}$ & 55 & 12.2 & 48 & 11.3 & $(1.0)$ \\
\hline -Yes & 396 & 87.8 & 377 & 88.7 & \\
\hline $\begin{array}{l}\text { Solar lentigines on } \mathrm{MM} \text { area }(\mathrm{mv}: 6 \\
[0.7 \%])\end{array}$ & & & & & $<0.001$ \\
\hline$-\mathrm{No}$ & 260 & 57.3 & 179 & 41.8 & $(<0.001)$ \\
\hline -Yes & 194 & 42.7 & 249 & 58.2 & \\
\hline
\end{tabular}

(Continued) 


\begin{tabular}{|c|c|c|c|c|c|}
\hline \multirow[b]{2}{*}{ Variable } & \multicolumn{2}{|c|}{$\begin{array}{l}\text { Nevi density on the MM area } \\
\text { lower or equal to total body nevi } \\
\text { density }\end{array}$} & \multicolumn{3}{|c|}{$\begin{array}{l}\text { Nevi density on the MM area } \\
\text { higher to total body nevi density }\end{array}$} \\
\hline & $\mathbf{N}$ & $\%$ & $\mathbf{N}$ & $\%$ & $\begin{array}{c}\mathbf{P} \\
(\mathbf{P c})\end{array}$ \\
\hline $\begin{array}{l}\text { Number of severe sunburns } \\
(\mathrm{mv}: 1[0.1 \%])\end{array}$ & & & & & 0.123 \\
\hline -No & 224 & 49.0 & 183 & 42.6 & $(1.0)$ \\
\hline$-1-5$ & 151 & 33.0 & 153 & 35.6 & \\
\hline$-6-10$ & 28 & 6.1 & 41 & 9.5 & \\
\hline$->10$ & 54 & 11.8 & 53 & 12.3 & \\
\hline $\begin{array}{l}\text { Sunburns at the MM area (mv: } 10 \\
{[1.1 \%] \text { ) }}\end{array}$ & & & & & $<0.001$ \\
\hline -No & 195 & 43.1 & 81 & 10.0 & $(<0.001)$ \\
\hline -Mild & 166 & 36.7 & 193 & 45.3 & \\
\hline -Intense & 91 & 20.1 & 152 & 35.7 & \\
\hline Histological subtype (mv: 0) & & & & & $<0.001$ \\
\hline$-\mathrm{LMM}$ & 73 & 15.9 & 24 & 5.6 & $(<0.001)$ \\
\hline -SSM & 264 & 57.6 & 317 & 73.7 & \\
\hline$-\mathrm{NM}$ & 61 & 13.3 & 71 & 16.5 & \\
\hline$-A L M$ & 30 & 6.6 & 1 & 0.2 & \\
\hline -Other/NOS & 30 & 6.6 & 17 & 4.0 & \\
\hline $\begin{array}{l}\text { Contiguous neval remnants (mv: } \\
32[3.6 \%] \text { ) }\end{array}$ & & & & & $<0.001$ \\
\hline -No & 358 & 81.2 & 279 & 67.2 & $(<0.001)$ \\
\hline -Yes & 83 & 18.8 & 136 & 32.8 & \\
\hline $\mathrm{CSD}(\mathrm{mv}:=301[33.9 \%])$ & & & & & $<0.001$ \\
\hline -No & 247 & 79.9 & 260 & 93.5 & $(<0.001)$ \\
\hline -Yes & 62 & 20.1 & 18 & 6.5 & \\
\hline Stage (mv: 0) & & & & & 0.986 \\
\hline -In situ & 80 & 17.5 & 74 & 17.2 & $(1.0)$ \\
\hline -Local disease & 316 & 69.0 & 301 & 69.5 & \\
\hline -Locoregional & 61 & 13.3 & 54 & 13.0 & \\
\hline -Metastatic & 1 & 0.2 & 1 & 0.2 & \\
\hline $\begin{array}{l}\text { Non-synonymous MC1R variants } \\
(\mathrm{mv}: 0)\end{array}$ & & & & & 0.181 \\
\hline -None & 155 & 36.7 & 125 & 30.7 & $(1.0)$ \\
\hline-1 variant & 160 & 37.9 & 172 & 42.3 & \\
\hline$->1$ variant & 107 & 25.4 & 110 & 27.0 & \\
\hline
\end{tabular}

P: p-value by Chi-squared test.

Pc: p-value corrected by Bonferroni test. 
Table 3: Age-adjusted multivariate regression model for the characteristics significantly associated to a site-specific relative nevus density higher than the total nevus density

\begin{tabular}{|c|c|c|c|}
\hline Variable & OR & $95 \% \mathrm{CI}$ & $\mathbf{P}$ \\
\hline Female vs. male & 0.5 & $0.4-0.8$ & 0.002 \\
\hline \multicolumn{4}{|c|}{ Total body nevi density: } \\
\hline$-<2.5$ & Ref. & Ref. & \\
\hline$-2.5-10.6$ & 4.2 & $2.6-6.8$ & $<0.001$ \\
\hline$->10.6$ & 6.5 & $3.9-10.9$ & $<0.001$ \\
\hline \multicolumn{4}{|c|}{ Sunburns at melanoma area: } \\
\hline -No & Ref. & Ref. & \\
\hline -Mild & 3.2 & $2.0-5.1$ & $<0.001$ \\
\hline -Intense & 3.9 & $2.3-6.6$ & $<0.001$ \\
\hline \multicolumn{4}{|l|}{ CSD } \\
\hline$-\mathrm{No}$ & Ref. & Ref. & 0.001 \\
\hline -Yes & 0.3 & $0.2-0.6$ & \\
\hline
\end{tabular}

Ref: Reference.

not know the purpose of the present study when providing this information.

In summary, we show that a higher nevus density at a given area increases the risk of developing melanoma at this site, particularly in male patients who have a high overall nevus density, a past personal history of sunburns at the site of melanoma. This is progressively and inversely correlated to histological evidence of chronic sun damage. Identifying these individuals at high-risk will help tailor surveillance and monitoring campaigns in the primary care setting.

\section{MATERIALS AND METHODS}

In this retrospective, observational study, data from the melanoma database of the Dermatology Department of the Instituto Valenciano de Oncologia (IVO), Valencia, Spain, were analyzed. This database, launched in 2000, has been regularly updated with data from all newly diagnosed and follow-up melanoma patients. Clinical, epidemiologic, and histological data are collected prospectively, including the medical history and physical examination of patients performed by interview by dermatologists with experience in melanoma management [29]. Specifically, nevus count was performed by an experienced dermatologist (E.N.) and included all unequivocal nevi (when appropriate this fact was assessed by dermoscopy) above $2 \mathrm{~mm}$ of diameter.

The present study was approved by our institution's Research Ethics Board. Informed consent was obtained from all participants.

Inclusion criteria were incident patients with invasive sporadic cutaneous melanoma, who had received definitive treatment at our institution between January 1, 2000, and December 31, 2014. Patients with extracutaneous melanomas and those with metastatic melanomas and unknown primary tumor were excluded.

The hypothesis of the study was that melanomas in patients with high number of total nevi develop mainly in areas with increased nevus density. Therefore, the primary outcome measure was the site-specific relative nevus density, which was defined as the ratio of the site specific nevus density to the total body nevus density for each person.

For the purpose of this study, we calculated the nevus density both according to overall skin surface and to the region where the melanoma had developed. Total body nevus density was calculated by dividing the number of common nevi greater than $2 \mathrm{~mm}$ in diameter by the body surface. This surface was defined according to the DuBois formula: (weight $\left.(\mathrm{kg})^{0.425}\right) \mathrm{x}$ (height $\left.(\mathrm{cm})^{0.725}\right) \times 0.007184-$ [35]. Nevus density at the melanoma region was calculated counting the number of nevi at the region where the melanoma presented and defining 'region' using Wallace's rule of nines to infer the proportion of total body surface: head $(9 \%$ of the total body surface), upper limb ( $7 \%$ excluding the hand), hand (2\%) anterior trunk (18\%), posterior trunk $(18 \%)$, lower limb (15\% excluding the foot), foot (3\%) [36]. Thereafter, three categories of nevus density at the melanoma area were defined by tertiles: $0 \mathrm{nevi} / \mathrm{m}^{2}$ (low density), 1-15 nevi $/ \mathrm{m}^{2}$ (intermediate density) and $>15$ nevi $/ \mathrm{m}^{2}$ (high density).

For the comparative analyses, the following variables were used: 
1. Epidemiological variables: age $(<45,45-60$, or $>60$ years), sex, melanoma location (head/neck, trunk, upper limb, lower limb, and acral locations).

2. Phenotypic traits: "photolocation" or melanoma location according to sun exposure patterns (rarely/nonexposed, occasionally exposed, usually exposed), number of common melanocytic nevi $(<20,20-50,51-100$ and $>100$ ), nevus density on the complete body surface (total number of nevi/square meters of body surface, further categorized according to tertiles into: $<2.5,2.5-10.6$ and $>10.6$ ), presence of solar lentigines, and presence of solar lentigines at the melanoma area.

3. Environmental factors: past personal lifetime history of severe sunburns (none, 1-5, 6-10, >10), past personal history of sunburns at the melanoma site (none, mild, intense).

4. Histopathological criteria: melanoma subtype (superficial spreading melanoma [SSM], lentigo maligna melanoma [LMM], nodular melanoma [NM], acral lentiginous melanoma $[\mathrm{ALM}]$ or other/nonspecified [Other/NOS]), contiguous neval remnants, solar elastosis (as a sign of cumulative sun-damage [CSD] and categorized in CSD vs. non-CSD according to previous classification [37]), and stage (in situ, local disease, locorregional disease, metastatic disease). All slides were reviewed by the same pathologist to avoid interobservational bias.

3. Germline susceptibility: presence of any nonsynonymous MC1R variants (Supplementary Table 1) determined by direct sequencing according to previously described methods and categorized into none, one or more than one variant [38].

We performed two independent comparisons. First, the aforementioned characteristics were compared between the three groups defined by the density of nevi within the melanoma primary site. Second, we compare the characteristics between the two groups defined by the site-specific relative nevus density: one group where the nevus density at the melanoma area was lower or equal to the total body nevus density (a ratio value less than or equal to one), and another in which it was higher (a ratio value greater than one).

The differences between the distributions of each variable in our groups were evaluated using Pearson's chisquare test. Odds ratios (OR) were calculated by univariate and age-adjusted stepwise forward multivariate logistic regression to assess the association of each variable to a site-specific relative nevus density higher than the total nevus density. All the statistical analyses were performed using the SPSS statistical package for Windows, version 20.0 (IBM Inc; Illinois, USA).

\section{CONFLICTS OF INTEREST}

The authors state no conflicts of interest.

\section{FUNDING}

This study has been supported partially by grant 2017-109-001 from the Universidad Católica de València and by grant PI15/01860 from the Fondo de Investigaciones Sanitarias del ISCIII. AV is funded by Wellcome Trust (110078/Z/15/Z).

\section{REFERENCES}

1. Whiteman DC, Parsons PG, Green AC. p53 expression and risk factors for cutaneous melanoma: a case-control study. Int J Cancer. 1998; 77:843-848.

2. Whiteman DC, Watt P, Purdie DM, Hughes MC, Hayward NK, Green AC. Melanocytic nevi, solar keratoses, and divergent pathways to cutaneous melanoma. J Natl Cancer Inst. 2003; 95:806-812.

3. Chiarugi A, Quaglino P, Crocetti E, Nardini P, De Giorgi V, Borgognoni L, Brandani P, Gerlini G, Manganoni AM, Bernengo MG, Pimpinelli N. Melanoma density and relationship with the distribution of melanocytic naevi in an Italian population: a GIPMe study--the Italian multidisciplinary group on melanoma. Melanoma Res. $2015 ; 25: 80-87$.

4. Echeverria B, Botella-Estrada R, Serra-Guillen C, Martorell A, Traves V, Requena C, Sanmartin O, Llombart B, Guillen C, Nagore E. [Increased risk of developing a second primary cutaneous nevus-associated melanoma in patients previously diagnosed with the disease]. [Article in Spanish]. Actas Dermosifiliogr. 2010; 101:710-716.

5. Bulliard JL. Site-specific risk of cutaneous malignant melanoma and pattern of sun exposure in New Zealand. Int J Cancer. 2000; 85:627-632.

6. Bulliard JL, De Weck D, Fisch T, Bordoni A, Levi F. Detailed site distribution of melanoma and sunlight exposure: aetiological patterns from a Swiss series. Ann Oncol. 2007; 18:789-794.

7. Caini S, Gandini S, Sera F, Raimondi S, Fargnoli MC, Boniol M, Armstrong BK. Meta-analysis of risk factors for cutaneous melanoma according to anatomical site and clinico-pathological variant. Eur J Cancer. 2009; 45:3054-3063.

8. Garbe C, Buttner P, Bertz J, Burg G, d'Hoedt B, Drepper H, Guggenmoos-Holzmann I, Lechner W, Lippold A, Orfanos CE, Peters A, Rassner G, Stadler R, Stroebel W. Primary cutaneous melanoma. Prognostic classification of anatomic location. Cancer. 1995; 75:2492-2498.

9. Kvaskoff M, Pandeya N, Green AC, Perry S, Baxter C, Davis MB, Mortimore R, Westacott L, Wood D, Triscott J, Williamson R, Whiteman DC. Site-specific determinants of cutaneous melanoma: a case-case comparison of patients with tumors arising on the head or trunk. Cancer Epidemiol Biomarkers Prev. 2013; 22:2222-2231. 
10. Naldi L, Adamoli L, Fraschini D, Corbetta A, Imberti L, Reseghetti A, Reciputo A, Rossi E, Cainelli T, Masera G. Number and distribution of melanocytic nevi in individuals with a history of childhood leukemia. Cancer. 1996; 77:1402-1408.

11. Pfahlberg A, Uter W, Kraus C, Wienecke WR, Reulbach $\mathrm{U}$, Kolmel KF, Gefeller O. Monitoring of nevus density in children as a method to detect shifts in melanoma risk in the population. Prev Med. 2004; 38:382-387.

12. Schuurman MS, de Waal AC, Thijs EJ, van Rossum MM, Kiemeney LA, Aben KK. Risk factors for second primary melanoma among Dutch melanoma patients. Br J Dermatol. 2017; 176:971-978.

13. Wachsmuth RC, Turner F, Barrett JH, Gaut R, RandersonMoor JA, Bishop DT, Bishop JA. The effect of sun exposure in determining nevus density in UK adolescent twins. J Invest Dermatol. 2005; 124:56-62.

14. Gallagher RP, Rivers JK, Yang CP, McLean DI, Coldman AJ, Silver HK. Melanocytic nevus density in Asian, IndoPakistani, and white children: the Vancouver Mole Study. J Am Acad Dermatol. 1991; 25:507-512.

15. Carli P, Naldi L, Lovati S, La Vecchia C. The density of melanocytic nevi correlates with constitutional variables and history of sunburns: a prevalence study among Italian schoolchildren. Int J Cancer. 2002; 101:375-379.

16. Purdue MP, From L, Armstrong BK, Kricker A, Gallagher RP, McLaughlin JR, Klar NS, Marrett LD. Etiologic and other factors predicting nevus-associated cutaneous malignant melanoma. Cancer Epidemiol Biomarkers Prev. 2005; 14:2015-2022.

17. Goldgar DE, Cannon-Albright LA, Meyer LJ, Piepkorn MW, Zone JJ, Skolnick MH. Inheritance of nevus number and size in melanoma and dysplastic nevus syndrome kindreds. J Natl Cancer Inst. 1991; 83:1726-1733.

18. Gibbs P, Brady BM, Robinson WA. The genes and genetics of malignant melanoma. J Cutaneous Med Surg. 2002; 6:229-235.

19. Gallagher RP, Rivers JK, Lee TK, Bajdik CD, McLean DI, Coldman AJ. Broad-spectrum sunscreen use and the development of new nevi in white children: a randomized controlled trial. JAMA. 2000; 283:2955-2960.

20. Barrett JH, Gaut R, Wachsmuth R, Bishop JA, Bishop DT. Linkage and association analysis of nevus density and the region containing the melanoma gene CDKN2A in UK twins. Br J Cancer. 2003; 88:1920-1924.

21. Florell SR, Meyer LJ, Boucher KM, Grossman D, Cannon-Albright LA, Harris RM, Samlowski WE, Zone JJ, Leachman SA. Increased melanocytic nevi and nevus density in a G-34T CDKN2A/p16 melanoma-prone pedigree. J Invest Dermatol. 2008; 128:2122-2125.

22. Florell SR, Meyer LJ, Boucher KM, Porter-Gill PA, Hart M, Erickson J, Cannon-Albright LA, Pershing LK, Harris RM, Samlowski WE, Zone JJ, Leachman SA. Longitudinal assessment of the nevus phenotype in a melanoma kindred. J Invest Dermatol. 2004; 123:576-582.

23. Purdue MP, From L, Kahn HJ, Armstrong BK, Kricker A, Gallagher RP, McLaughlin JR, Klar NS, Marrett LD. Etiologic factors associated with p53 immunostaining in cutaneousmalignant melanoma. Int J Cancer. 2005; 117:486-493.

24. Welkovich B, Landthaler M, Schmoeckel C, Braun-Falco O. [The number and distribution of nevus cell nevi in patients with malignant melanoma]. [Article in German]. Hautarzt. 1989; 40:630-635.

25. Rodenas JM, Delgado-Rodriguez M, Farinas-Alvarez C, Herranz MT, Serrano S. Melanocytic nevi and risk of cutaneous malignant melanoma in southern Spain. Am J Epidemiol. 1997; 145:1020-1029.

26. Olsen CM, Zens MS, Stukel TA, Sacerdote C, Chang YM, Armstrong BK, Bataille V, Berwick M, Elwood JM, Holly EA, Kirkpatrick C, Mack T, Bishop JN, et al. Nevus density and melanoma risk in women: a pooled analysis to test the divergent pathway hypothesis. Int J Cancer. 2009; 124:937-944.

27. Randi G, Naldi L, Gallus S, Di Landro A, La Vecchia C. Number of nevi at a specific anatomical site and its relation to cutaneous malignant melanoma. J Invest Dermatol. 2006; 126:2106-2110.

28. Rieger E, Soyer HP, Garbe C, Buttner P, Kofler R, Weiss J, Stocker U, Kruger S, Roser M, Weckbecker J, Panizzon $\mathrm{R}$, Bahmer F, Tilgen W, et al. Overall and site-specific risk of malignant melanoma associated with nevus counts at different body sites: a multicenter case-control study of the German Central Malignant-Melanoma Registry. Int J Cancer. 1995; 62:393-397.

29. Nagore E, Botella-Estrada R, Requena C, Serra-Guillen C, Martorell A, Hueso L, Llombart B, Sanmartin O, Guillen C. [Clinical and epidemiologic profile of melanoma patients according to sun exposure of the tumor site]. [Article in Spanish]. Actas Dermosifiliogr. 2009; 100:205-211.

30. Montero I, Requena C, Traves V, Garcia-Casado Z, Kumar R, Nagore E. Age-related characteristics of cutaneous melanoma in a Spanish Mediterranean population. Int J Dermatol. 2015; 54:778-784.

31. Pena-Vilabelda MM, Garcia-Casado Z, Requena C, Traves V, Lopez-Guerrero JA, Guillen C, Kumar R, Nagore E. Clinical characteristics of patients with cutaneous melanoma according to variants in the melanocortin 1 receptor gene. Actas Dermosifiliogr. 2014; 105:159-171.

32. Kumar R, Angelini S, Snellman E, Hemminki K. BRAF mutations are common somatic events in melanocytic nevi. J Invest Dermatol. 2004; 122:342-348.

33. Bataille V, Sasieni P, Grulich A, Swerdlow A, McCarthy W, Hersey P, Newton Bishop JA, Cuzick J. Solar keratoses: a risk factor for melanoma but negative association with melanocytic naevi. Int J Cancer. 1998; 78:8-12. 
34. Kvaskoff M, Pandeya N, Green AC, Perry S, Baxter C, Davis MB, Mortimore R, Westacott L, Wood D, Triscott J, Williamson R, Whiteman DC. Solar elastosis and cutaneous melanoma: a site-specific analysis. Int J Cancer. 2015; 136:2900-2911.

35. DuBois D, DuBois E. A formula to estimate the approximate surface area if height and weight be known. Arch Int Med. 1916; 17:683-871.

36. Wallace AB. The exposure treatment of burns. 1951; 1:501-504.
37. Landi MT, Bauer J, Pfeiffer RM, Elder DE, Hulley B, Minghetti P, Calista D, Kanetsky PA, Pinkel D, Bastian BC. MC1R germline variants confer risk for BRAF-mutant melanoma. Science. 2006; 313:521-522.

38. Garcia-Casado Z, Traves V, Banuls J, Niveiro M, GimenoCarpio E, Jimenez-Sanchez AI, Moragon M, Onrubia JA, Oliver V, Kumar R, Nagore E. BRAF, NRAS and $\mathrm{MC} 1 \mathrm{R}$ status in a prospective series of primary cutaneous melanoma. Br J Dermatol. 2015; 172:1128-1131. 